\title{
Paternity in male kidney transplant recipients: a French national survey, the PATeRNAL study
}

\author{
Annabel Boyer ${ }^{1,2^{*}}$ (D) Thierry Lobbedez ${ }^{1,2,3}$, Mohamed Ouethrani ${ }^{1}$, Angélique Thuillier Lecouf ${ }^{1}$, Nicolas Bouvier ${ }^{1,3}$,
} Valérie Châtelet ${ }^{1,2,3}$, Bruno Hurault de Ligny ${ }^{1,3}$ and On behalf of the Spiesser transplant group

\begin{abstract}
Background: There is concern about the impact of immunosuppressive agents taken by male kidney transplant (KT) recipients on the risk of foetal malformations. The aim of our survey was to estimate the paternity rate and the outcomes of pregnancies fathered by kidney transplanted males.

Methods: This survey analysed 1332 male KT recipients older than 18 years, followed in 13 centres in France. A selfreported questionnaire was used to collect data on the patients, treatments at the time of conception and the pregnancy outcomes.

Results: The study included data on 349 children from 404 pregnancies fathered by 232 male KT recipients. The paternity rate was $17 \%$ (95\% Cl [15-20]). There were 37 (9\%, 95\% Cl [7-12]) spontaneous abortions, 12 (3\%, 95\% Cl [2-5]) therapeutic abortions, $2(0.5 \%, 95 \% \mathrm{Cl}[0.1-1])$ still births, and $13(4 \%, 95 \% \mathrm{Cl}$ [2-6]) malformations reported. Compared to the general population, there was no difference in the proportion of congenital malformations nor unwanted outcomes whether the father was exposed or not to immunosuppressive agents.
\end{abstract}

Conclusions: This survey does not provide any warning signal that pregnancies fathered by male patients exposed to immunosuppressive agents, notably the debated MMF/MPA, have more complications than pregnancies in the general population.

Keywords: Paternity, Kidney transplant, Pregnancy, Congenital malformation, Immunosuppression

\section{Background}

The first child of a kidney transplant recipient was born in 1958. Pregnancy is currently considered one of the benefits accorded to women by kidney transplantation [1]. Despite early concerns about the teratogenicity of immunosuppressive medication, thousands of solid organ transplant recipients worldwide have had successful pregnancies after transplantation [2-9]. In 1991, the

\footnotetext{
* Correspondence: annabel.boyer@wanadoo.fr

'Centre Universitaire des Maladies Rénales, CHU de Caen, Avenue de la côte de Nacre, 14033 Caen, Cedex 9, France

${ }^{2}$ U1086 INSERME - ANTICIPE, Centre Régional de Lutte contre le Cancer, François Baclesse, 14076 Caen, Cedex 5, France

Full list of author information is available at the end of the article
}

National Transplantation Pregnancy Registry (NTPR) was created to collect information on the outcomes of pregnancies among transplant recipients in North America [10].

Pregnancy in transplanted patients remains a challenge because of the increased risk of adverse maternal complications and adverse foetal outcomes [2-4, 7-9, 11]. In addition, immunosuppressive medications, such as sirolimus and mycophenolate mofetil/mycophenolic acid (MMF/MPA), have been associated with an increased incidence of foetal malformations $[5,6,12-16]$. A specific pattern of malformation has been described with MMF/MPA exposure during pregnancy, including microtia, cleft lip and

(c) The Author(s). 2020 Open Access This article is licensed under a Creative Commons Attribution 4.0 International License, which permits use, sharing, adaptation, distribution and reproduction in any medium or format, as long as you give appropriate credit to the original author(s) and the source, provide a link to the Creative Commons licence, and indicate if changes were made. The images or other third party material in this article are included in the article's Creative Commons licence, unless indicated otherwise in a credit line to the material. If material is not included in the article's Creative Commons licence and your intended use is not permitted by statutory regulation or exceeds the permitted use, you will need to obtain permission directly from the copyright holder. To view a copy of this licence, visit http://creativecommons.org/licenses/by/4.0/ The Creative Commons Public Domain Dedication waiver (http://creativecommons.org/publicdomain/zero/1.0/) applies to the data made available in this article, unless otherwise stated in a credit line to the data. 
palate, and congenital heart defects $[4,6,13-17]$. These data led the Food and Drug Administration to change the pregnancy category of MMF/MPA from $\mathrm{C}$ to $\mathrm{D}$ (positive evidence of human foetal risk, potential benefits may warrant its use despite the potential risk) in October 2007 [18]. There are guidelines for female kidney transplant (KT) recipients regarding the timing of pregnancy and the management of immunosuppressive therapy. MMF/MPA and sirolimus should be discontinued and replaced by another drug at least six weeks prior to conception $[5,7,12,19-21]$.

Information on fertility and the outcomes of pregnancies fathered by male KT recipients is sparse [4, 5, 22-24]. Some clinicians have expressed concern about the effect of immunosuppressive agents taken by the father at the time of conception on the risk of foetal malformation. Data from the NTPR are reassuring since the outcomes of pregnancies fathered by male KT recipients were similar to those from the general population [5, 22]. No pattern of malformation was observed in the offspring of 152 male recipients who were on MMF/MPA at the time of conception [4, 22]. In two population-based studies conducted in Norway, the risk of malformation was not increased when the father was on MMF/MPA at the time of conception [23, 24]. There is a lack of data regarding the fertility rate in men under immunosuppressive therapy after a kidney transplantation. A higher incidence of infertility in transplanted patients on sirolimus has been observed [4, 25-29].

Based on in vitro studies [30], the European Medicines Agency (EMA), and hence the French Agence Nationale de la Santé et des Médicaments (ANSM), have recommended since October 2015 that sexually active men treated with MMF/MPA must use effective contraception until at least 90 days after the cessation of MMF/ MPA [31-33]. It was initially recommended that their female partners also use effective contraception during the same period. Since 2017, it is no longer advocated that both partners use contraception [34]. This recommendation is a matter of concern for the transplant teams and for the transplanted patients as planned fatherhood would require changing MMF/MPA for another immunosuppressive agent, which could increase the risk of rejection. It also raises the question of pregnancy termination in cases of paternal exposure to MMF/MPA. In the absence of scientific evidence, some authors urged the EMA to reconsider their position, or provide data to support it [35-37]. The current information in the literature is insufficient to allow institutions to make evidence-based decisions and thus additional studies are needed.

In the absence of reliable data, we aimed to conduct a nationwide survey of male transplanted patients followed in 13 centres in France. This survey was carried out to determine the paternity rate of male transplanted patients and to estimate the outcomes of pregnancies fathered by male KT recipients under immunosuppressive therapy at the time of conception.

\section{Methods \\ Study population}

This national survey was conducted by the Spiesser transplant group in France, which was created in 1997 and includes 13 of the 31 adult transplant centres in order to develop research protocols and share experiences in the field of renal transplantation. All male adults older than 18 years who lived in France and had received at least one kidney transplant in one of the participating centres between the January 1, 2005, and December 31, 2014, were included. Patients older than 60 years at the time of first transplantation, under guardianship, multi-organ transplanted or those who refused to participate were excluded from the survey.

\section{Objectives}

The survey was carried out to seek for a signal of increased adverse pregnancy outcomes across male KT participants. Thus, the main objective was to determine the paternity rate in our population. The secondary objectives were to describe the outcome of pregnancies fathered by KT recipients under immunosuppressive therapy at the time of conception, and to investigate a possible future desire to father a child.

\section{Method}

The survey was distributed by post between January 2018 and February 2019, with a pre-stamped return envelope, to male transplanted patients included in the study. A second dispatch was sent out to increase the number of responders. Two months after the first and second dispatches, a relaunch was sent to patients who had not responded, to maximise the number of participants.

A self-reported questionnaire, developed for this survey and adapted with authorization from the NTPR questionnaire, was used [38]. The questionnaire was divided into four sections and contained 32 items (Supplementary data, Figure S1). The collected data included global information on the patient: age, reference centre and year of kidney transplantation, number of children, and number of children after transplantation. If the patient did not have children, we collected information on the reasons why: anxiety, infertility, no desire. If the patient had children after transplantation, the collected data included: the year of pregnancy, the immunosuppressive agents taken at the time of conception and the pregnancy outcomes (miscarriage, stillbirth, livebirth, birth term, birth weight, congenital malformation, cognitive impairment). The last section of our questionnaire 
collected data on a possible future desire to father a child.

\section{Statistical analysis}

Continuous variables are described by their median and interquartile range (IQR). Categorical variables are described by frequencies, percentage and their 95\% confidence interval ( $95 \% \mathrm{CI})$. Missing data on our primary objective were less than $5 \%$ and were considered missing at random. Missing data on the other variables were as follow: less than $5 \%$ on patients' characteristics, treatment at the time of conception and pregnancy outcomes (living birth, spontaneous abortion, therapeutic abortion, stillbirth, malformation); and 8,11 and $12 \%$ on the birth weight, gestational age and year of pregnancy respectively. Analyses were performed with R 3.4.3 (R Foundation for Statistical Computing, Vienna, Austria).

The study was approved by the ethics committee of $\mathrm{CHU}$ de Caen and was conducted according to the declaration of Helsinki.

\section{Results}

\section{Participants characteristics}

Of the 3321 eligible male KT recipients, there were 413 (12\%) missing addresses. Among the 2908 subjects who received the questionnaire, 1332 completed the survey (46\% respond rate) (Fig. 1). Supplementary data Table S1 details the number of participants per centre. Participants with and without children were distributed equally across the 13 centres. Our population median age was of 55 years old [IQR 46-62]. The participants' characteristics are described in Supplementary data Table S2.

\section{Paternity rate}

With 232 participants having at least one child after transplantation, the paternity rate in our population was $17 \%$ (95\% CI [15-20]), with on average 2 children after renal transplantation. Of these, 62 (27\%, 95\% CI [2133]) male KT recipients had experienced fertility issues that were solved with medically assisted reproduction. A total of $1100(83 \%, 95 \%$ CI [80-85]) participants did not have a child after renal transplantation: 330 (25\%, 95\% CI [22-27]) never had a child at all, and 770 (58\%, 95\% CI [55-60]) had children before transplantation only.

\section{Participants without children after transplantation}

Of the 330 participants who never had a child, 105 (32\%, 95\% CI [27-37]) declared that they did not want to conceive after transplantation, $6(2 \%, 95 \%$ CI [0.7-4]) male $\mathrm{KT}$ recipients were concerned about the risk of transmission of polycystic kidney disease (PKD), whereas 55 (17\%, 95\% CI [13-21]) suffered from infertility (Table 1). Childless participants seemed to be younger than the ones who had fathered children before KT only, with a median age of 50 years [IQR 39-59] and 59 years [IQR 53-64] respectively (Table 1 ).

\section{Outcome of pregnancies fathered by male kidney transplant recipients under immunosuppressive therapy at the time of conception}

There were 349 children from 404 pregnancies fathered by 232 male KT recipients, including twin pregnancies. Unwanted outcomes occurred in the 404 pregnancies as follows: 37 (9\%, 95\% CI [7-12]) spontaneous abortions, $12(3 \%, 95 \%$ CI [2-5]) therapeutic abortions, and 2 $(0.5 \%, 95 \%$ CI $[0.1-1])$ still births. There were $10(2 \%$, 95\% CI [1-5]) ongoing pregnancies at the time of the survey. Of the 349 living births, the median gestational age was 41 weeks (IQR [39-41]), with only 30 (9\%, 95\% CI [6-12]) pre-term deliveries. The median birth weight was $3.4 \mathrm{Kg}$ (IQR [3-3.7]). There were 13 (4\%, 95\% CI [2-6]) congenital malformations reported (Table 2).

The outcomes of pregnancies fathered by male KT recipients according to the father's immunosuppressive medication at the time of conception are described in Tables 3 and 4 . The immunosuppressive agents and the malformations or therapeutic abortions are displayed in Table 5. Since before the pregnancies the male patients were exposed to co-medication, outcomes can be declared in several columns. Of the 5 pregnancies within the partnerships of the participants treated by everolimus, there was one therapeutic abortion due to multiple malformations. The proportion of therapeutic abortions and malformations according to the immunosuppressive agents taken by the father were: 6 of $59(10 \%, 95 \%$ CI [4-21]) pregnancies for azathioprine (AZA), 18 of 255 (7\%, 95\% CI [4-11]) pregnancies for tacrolimus, 19 of 298 (6\%, 95\% CI [4-10]) pregnancies for corticosteroid (CTC), 17 of 313 (5\%, 95\% CI [3-9]) pregnancies for MMF/MPA, and 6 of 152 (4\%, 95\% CI [1-8]) pregnancies for cyclosporine. The most common treatment associations were: CTC - MMF/MPA - tacrolimus (159 pregnancies conceived by 103 patients) and CTC MMF/MPA - cyclosporine (72 pregnancies conceived by 45 patients), with a malformation rate of $3.7 \%(95 \%$ CI $[1.5-8])$ and $1.4 \%(95 \%$ CI [0.7-8.5]) respectively.

\section{Willingness of having a child in male transplanted patients under immunosuppressive therapy}

In the cohort, 175 (13\%, 95\% CI [11-15]) participants reported having a desire to father a child in the future, while 140 (11\%, 95\% CI [9-12]) felt anxious about fathering a child while taking immunosuppressive medications. Of these 175 subjects, 50 (4\%, 95\% CI [3-5]) patients have had treatment modifications linked to their willingness to conceive. Table 6 describes the patients' feelings regarding a future pregnancy according to their fatherhood status. 
3321 screened patients

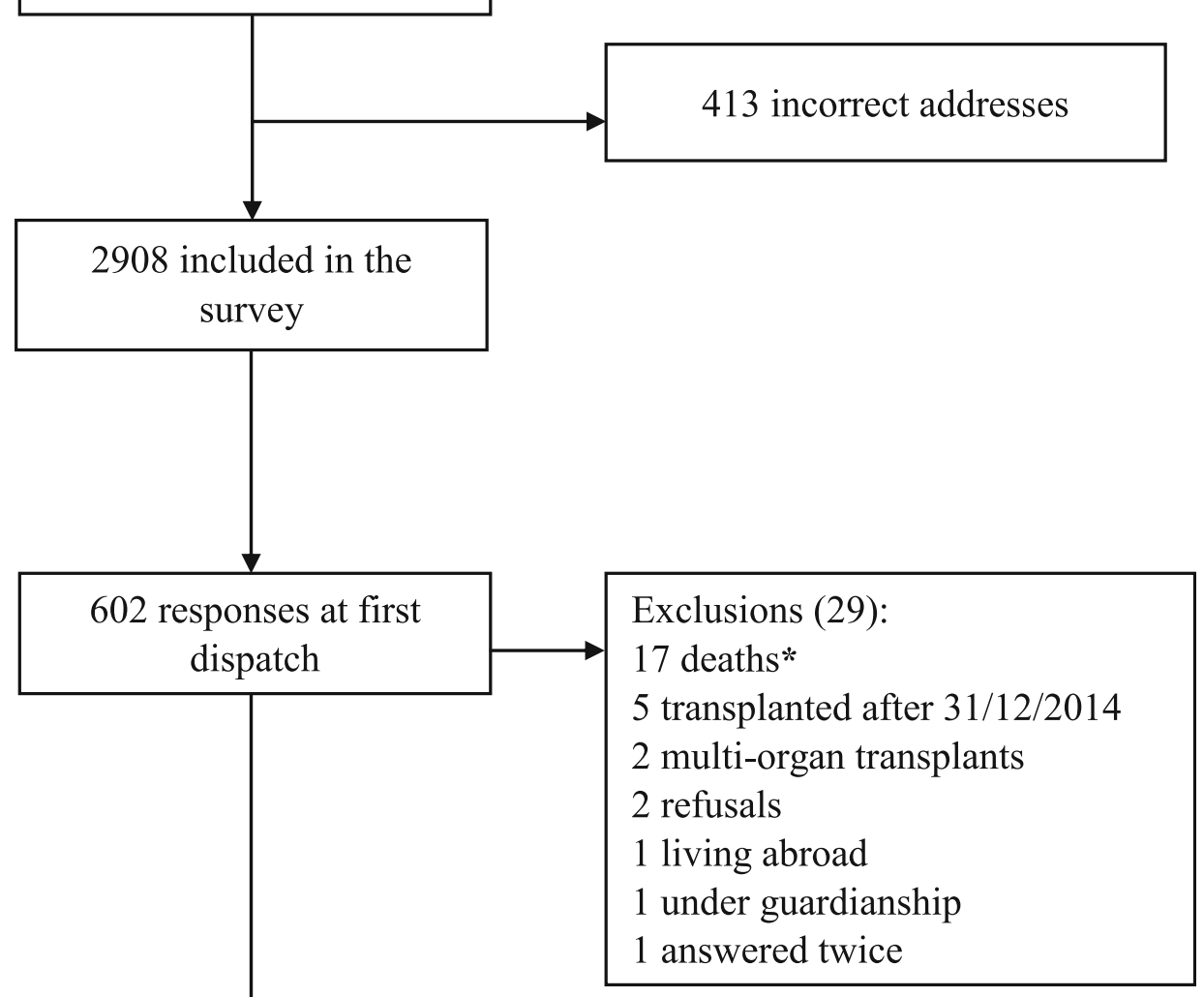

17 deaths*

5 transplanted after 31/12/2014

2 multi-organ transplants

2 refusals

1 living abroad

under guardianship
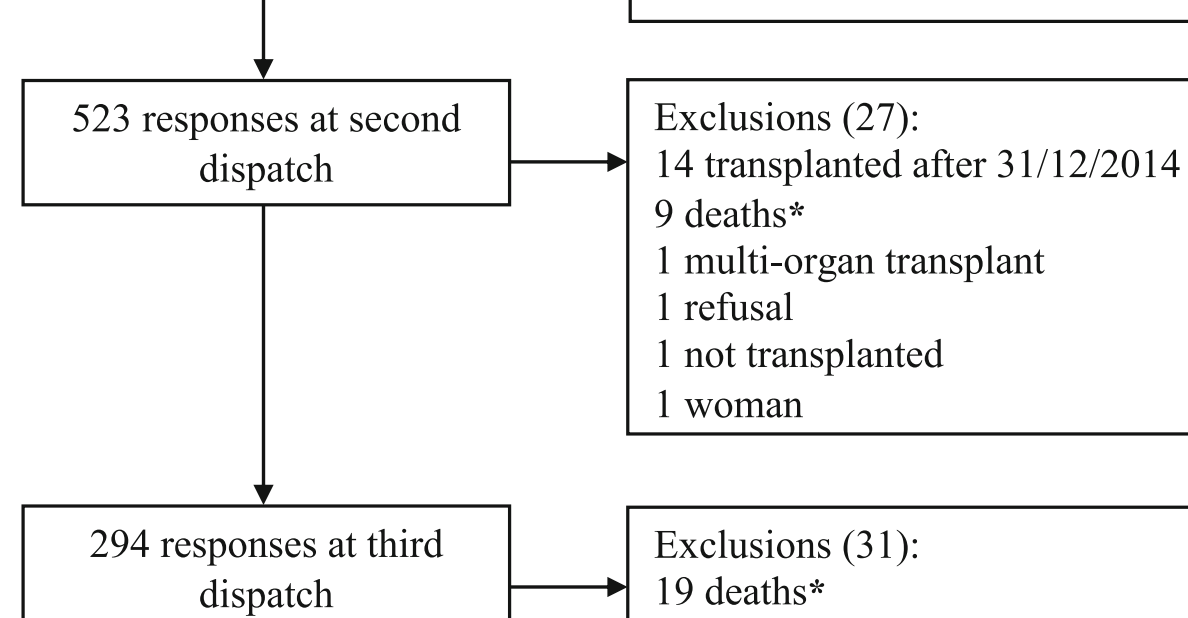

Exclusions (31):

19 deaths*

9 transplanted after 31/12/2014

1 multi-organ transplant

1 refusal

1 under guardianship

1332 participants included in the analysis

Fig. 1 Flow chart. * Surveys were sent back by family members, with a notice of the patients' recent death 
Table 1 Description of participants without children

\begin{tabular}{ll}
\hline Covariate & Childless patients $(\boldsymbol{n}=\mathbf{3 3 0})$ \\
\hline Age, median (IQR), years & $50(39-59)$ \\
Year of first transplantation, median (IQR) & $2009(2005-2012)$ \\
Reason, n (\%, [95\% CI]) & $105(32 \%,[27-37])$ \\
No desire to father a child & $55(17 \%,[13-21])$ \\
Infertility & $5(1 \%,[0.5-4])$ \\
$\quad$ Erectile dysfunction & $33(10 \%,[7-14])$ \\
Spermatogenesis disorders & $17(5 \%,[3-8])$ \\
Other & $37(11 \%,[8-15])$ \\
Anxiety & $7(2 \%,[1-4])$ \\
Other & $75(23 \%,[18-28])$ \\
Age & $6(2 \%,[0.7-4])$ \\
Celibacy & $11(3 \%,[2-6])$ \\
Genetic PKD & $4(1 \%,[0.3-3])$ \\
Genetic disease other than PKD & $3(1 \%,[0.2-3])$ \\
Intellectual disability & $27(8 \%,[5-12])$ \\
Partner's infertility & $4(1 \%,[0.3-3])$ \\
Missing &
\end{tabular}

IQR interquartile range, $P K D$ polycystic kidney disease

\section{Discussion}

Successful transplantation improves reproductive function, permitting male $\mathrm{KT}$ recipients to father children $[22,39,40]$. The impact of immunosuppressive medication on the fertility of male KT recipients and their offspring is however unknown, since data related to paternal exposure at the time of conception are sparse. We hereby provide an estimation, based on a survey, of the proportion of male $\mathrm{KT}$ recipients having fathered children, and the outcome of the pregnancies.

We report a paternity rate in our population of $17 \%$, a majority of the participants did not have children after renal transplantation.

\section{Infertility issues}

The reported infertility rate in our childless population has been estimated at 17\% mainly because of spermatogenesis disorders, higher than that in the general population (Table 1). In France, among $10-15 \%$ of couples who suffer from infertility, approximately $20-30 \%$ have a male origin [41]. It is generally assumed that approximately 6$7 \%$ of men face fertility problems [42-44]. Immunosuppressive agents, notably sirolimus, have been associated with impaired fertility after transplant [25, 27-29]. In a study from Zuber et al. [29], the proportion of patients who had fathered after KT was significantly lower in patients treated with sirolimus, with abnormalities in sperm analysis. Our results highlight that $27 \%$ of patients who had fathered a child after KT needed medically assisted reproduction, with an equal proportion in each group of immunosuppressive agents. The issue of male fertility in kidney transplant recipients requires additional studies.

\section{Outcome of pregnancies fathered by male kidney transplant recipients under immunosuppressive therapy at the time of conception}

This is to date one of the largest cohorts, apart from the NTPR reports, regarding paternity in transplanted patients $[4,5,22]$. In our population, $86,9,3$ and $0.5 \%$ of respectively livebirths, spontaneous abortions, therapeutic abortions and stillbirths, occurred. The higher occurrence of unwanted outcomes observed in pregnancies fathered by patients treated with everolimus, sirolimus and belatacept should be interpreted with caution as only a few patients were exposed to these agents. Of note, the occurrence of spontaneous abortion in the general population varies between 12 and $15 \%$ of pregnancies [45]. In France, authorizations for therapeutic abortion are delivered in approximately $0.93 \%$ of pregnancies [46], a lower rate than the one observed in our population. The general population stillbirth rate varies from 0.9 to $0.4 \%$ [47], which is similar to our results.

In our study, among the 349 livebirths, only $9 \%$ were pre-term delivered, $6 \%$ had low birth-weights $<2.5 \mathrm{Kg}$, and $4 \%$ had malformations. It should be noted that there was a higher rate of pre-term delivery in pregnancies fathered by patients treated with everolimus, and a higher rate of low birth-weight in pregnancies fathered by patients treated with sirolimus. These results should be interpreted very cautiously as only 5 and 7 patients were treated with everolimus and sirolimus, respectively. In the general population, the pre-term delivery and low birth-weight rates are $7.5 \%$, and birth defects occur in approximately $2-3 \%$ of newborns [48, 49].

Our study shows that there was no difference in the proportion of congenital malformations whether the father was exposed or not to immunosuppressive agents. Reports and analyses from the NTPR concluded that the outcomes of pregnancies fathered by male transplant recipients were similar to those of the general population. In 2010, Coscia et al. [5] reported 902 pregnancies fathered by 591 male KT recipients, with $93 \%$ livebirths but birth defects were not described. A Norwegian study reported 474 children born after transplantation, and no increased risk was found for any pregnancy outcomes compared with the general population, with a malformation rate of $1.9 \%$ [23]. Of the 13 congenital malformations in our population, 3 (one congenital phimosis, one pyloric stenosis and one Wolf Parkinson White syndrome) are well known malformations that have never been associated with any medication [50-52]. 
Table 2 Description and outcomes of pregnancies fathered by male kidney transplant patients

\begin{tabular}{|c|c|c|c|c|c|}
\hline Covariate & $\begin{array}{l}\text { All pregnancies } \\
n=404\end{array}$ & $\begin{array}{l}\text { First pregnancy } \\
n=245\end{array}$ & $\begin{array}{l}\text { Second pregnancy } \\
n=115\end{array}$ & $\begin{array}{l}\text { Third pregnancy } \\
n=35\end{array}$ & $\begin{array}{l}\text { Fourth pregnancy } \\
n=9\end{array}$ \\
\hline Age, median (IQR), years & $41(36-48)$ & $41(36-48)$ & $42(37-48)$ & $43(37.5-49)$ & $48(44-52)$ \\
\hline Age at conception, median (IQR), years & $34(30-37)$ & $33(21-36)$ & $35(31-39)$ & $37(34-40)$ & $41(40-44)$ \\
\hline Year of first transplantation, median (IQR) & $2006(1999-2010)$ & 2006 (1999-2010) & $2006(1996-2008)$ & $2005(1994-2007)$ & $1994(1986-2002)$ \\
\hline $\begin{array}{l}\text { Transplant to conception time in years, } \\
\text { median (IQR) }\end{array}$ & $5(2-8)$ & $4(1.5-7)$ & $7(4-10)$ & $8(6-11)$ & $16(13-19)$ \\
\hline \multicolumn{6}{|c|}{ Immunosuppressive co-medication at the time of conception ${ }^{a}$} \\
\hline Corticosteroids & $298(74 \%,[69-78])$ & $176(72 \%,[66-77])$ & $84(73 \%,[64-81])$ & $29(83 \%,[66-93])$ & $9(100 \%,[66-100])$ \\
\hline Azathioprine & $59(15 \%,[11-18])$ & $44(18 \%,[13-23])$ & $13(11 \%,[6-19])$ & $1(3 \%,[0.7-15])$ & $1(11 \%,[0.3-50])$ \\
\hline MMF/MPA & 313 (77\%, [73-81]) & 190 (78\%, [72-83]) & $92(80 \%,[72-87])$ & $26(74 \%,[57-88])$ & $5(56 \%,[21-86])$ \\
\hline Tacrolimus & $255(63 \%,[58-68])$ & 156 (64\%, [57-70]) & $70(61 \%,[51-70])$ & $22(63 \%,[45-79])$ & 7 (78\%, [40-97]) \\
\hline Cyclosporine & $152(38 \%,[33-43])$ & $94(38 \%,[32-45])$ & $43(37 \%,[29-47])$ & $13(37 \%,[21-55])$ & $2(22 \%,[3-60])$ \\
\hline Everolimus & $5(1 \%,[0.5-3])$ & $3(1 \%,[0.3-4])$ & $2(2 \%,[0.2-6])$ & $0(0 \%,[0-10])$ & $0(0 \%,[0-33])$ \\
\hline Sirolimus & $7(2 \%,[1-4])$ & $5(2 \%,[0.7-5])$ & $2(2 \%,[0.2-6])$ & $0(0 \%,[0-10])$ & $0(0 \%,[0-33])$ \\
\hline Belatacept & $6(1 \%,[0.5-3])$ & $4(2 \%,[0.4-4])$ & $1(1 \%,[0.1-5])$ & $1(3 \%,[0.7-15])$ & $0(0 \%,[0-33])$ \\
\hline Other $^{\mathrm{b}}$ & $40(10 \%,[7-13])$ & $18(7 \%,[4-11])$ & $16(14 \%,[8-22])$ & $5(14 \%,[5-30])$ & $1(11 \%,[0.3-50])$ \\
\hline $\begin{array}{l}\text { Rejection episode before or during } \\
\text { pregnancy }\end{array}$ & $80(20 \%,[16-24])$ & $40(16 \%,[12-22])$ & $29(25 \%,[18-34])$ & $8(23 \%,[10-40])$ & $3(33 \%,[7-70])$ \\
\hline \multicolumn{6}{|l|}{ Pregnancy outcomes } \\
\hline $\begin{array}{l}\text { Live births, including } 6 \text { twin } \\
\text { pregnancies }\end{array}$ & 349 (86\%, [83-90]) & 222 (91\%, [86-94]) & $94(82 \%,[73-88])$ & $26(74 \%,[57-88])$ & 7 (78\%, [40-97]) \\
\hline Twin pregnancy & $7(2 \%,[0.5-3])$ & $5(2 \%,[0.7-5])$ & $1(1 \%,[0.1-5])^{c}$ & $1(3 \%,[0.7-15])$ & $0(0 \%,[0-33])$ \\
\hline Spontaneous abortion & 37 (9\%, [7-12]) & $18(7 \%,[4-11])$ & $14(12 \%,[7-20])$ & $4(11 \%,[3-27])$ & $1(11 \%,[0.3-50])$ \\
\hline Therapeutic abortion & $12(3 \%,[2-5])$ & $6(2 \%,[0.9-5])$ & $2(2 \%,[0.2-6])$ & $3(9 \%,[2-23])$ & $1(11 \%,[0.3-50])$ \\
\hline Still births & $2(0.5 \%,[0.1-1])$ & $0(0 \%,[0-0.1])$ & $0(0 \%,[0-3])$ & $2(6 \%,[1-19])$ & $0(0 \%,[0-33])$ \\
\hline Ongoing pregnancy & $10(2 \%,[1-5])$ & $4(2 \%,[0.4-4])$ & $5(4 \%,[1-10])$ & $1(3 \%,[0.7-15])$ & $0(0 \%,[0-33])$ \\
\hline Live births, including twin pregnancies & 349 & 222 & 94 & 26 & 7 \\
\hline Gestational age in weeks, median (IQR) & $41(39-41)$ & $41(38-41)$ & $41(39-41)$ & $41(39-41)$ & $41(39-41)$ \\
\hline Pre-term delivery ( $<37$ weeks) & $30(9 \%,[6-12])$ & $23(10 \%,[7-15])$ & $5(5 \%,[2-12])$ & $2(8 \%,[1-25])$ & $0(0 \%,[0-41])$ \\
\hline Birthweight (Kg), median (IQR) & $3.4(3-3.7)$ & $3.3(3-3.7)$ & $3.4(3-3.8)$ & $3.5(3-3.6)$ & $3.5(3.2-3.8)$ \\
\hline Low birthweight $(<2.5 \mathrm{Kg})$ & $20(6 \%,[4-9])$ & $16(7 \%,[4-11])$ & $3(3 \%,[1-9])$ & $1(4 \%,[0.1-20])$ & $0(0 \%,[0-41])$ \\
\hline Sex (male) & $193(55 \%,[50-61])$ & $127(57 \%,[50-64])$ & $47(50 \%,[40-60])$ & $16(62 \%,[41-80])$ & $3(43 \%,[10-82])$ \\
\hline Intellectual disability & $3(1 \%,[0.2-3])$ & $3(1 \%,[0.3-4])$ & $0(0 \%,[0-4])$ & $0(\%,[0-13])$ & $0(0 \%,[0-41])$ \\
\hline Congenital malformation & $13(4 \%,[2-6])$ & $10(5 \%,[2-8])$ & $3(3 \%,[1-9])$ & $0(\%,[0-13])$ & $0(0 \%,[0-41])$ \\
\hline
\end{tabular}

Values are presented as numbers and percentages $[95 \% \mathrm{Cl}]$ unless otherwise specified

IQR interquartile range, MMF/MPA mycophenolate mofetil/mycophenolic acid, $\mathrm{Kg}$ Kilograms

${ }^{a}$ Immunosuppressive agents of the father at the time of conception, more than one co-medication possible

${ }^{b}$ Other: Immunosuppression including one of the following treatment before or at the time of conception: Cyclophosphamide, Intravenous immunoglobulin,

Plasma exchange, Rituximab

${ }^{\mathrm{c}}$ The twin pregnancy was still ongoing at the time of the study

Paternal exposure to MMF/MPA at the time of conception There has been increasing concern since the EMA recommendations on the precautions male KT recipients should take while being treated with MMF/MPA [32, 33, 35-37]. These recommendations rely on the theoretical potential of chromosomal damage due to the transfer of MMF/ MPA through seminal fluid [30, 35]. In our study, pregnancies were mostly conceived under the following medications: CTC, MMF/MPA and tacrolimus, which is currently the most common post-transplant combination worldwide [24]. The malformation rates were 4, 3 and 5\% respectively, without highlighting any over-representation of malformations under MMF. The highest malformation rate $(10 \%)$ was observed with azathioprine exposure. Jones 
Table 3 Description and outcomes of pregnancies fathered after kidney transplantation according to the fathers' immunosuppressive medication at the time of conception

\begin{tabular}{|c|c|c|c|c|}
\hline Covariate & $\begin{array}{l}\text { MMF/MPA } \\
n=313\end{array}$ & $\begin{array}{l}\text { CTC } \\
n=298\end{array}$ & $\begin{array}{l}\text { Tacrolimus } \\
n=255\end{array}$ & $\begin{array}{l}\text { Cyclosporine } \\
n=152\end{array}$ \\
\hline Number of recipients & 195 & 177 & 166 & 94 \\
\hline Age, median (IQR), years & $40(36-45)$ & $43(37-50)$ & $40(35-45)$ & $46(38-52)$ \\
\hline Age at conception, median (IQR), years & $34(30-38)$ & $34(31-38)$ & $35(31-38)$ & $33(29-37)$ \\
\hline Transplant to conception time ${ }^{a}$, median (IQR) & $5(2-9)$ & $5(3-10)$ & $5(7-10)$ & $4(2-7.5)$ \\
\hline \multicolumn{5}{|l|}{ Pregnancy outcomes } \\
\hline Live births, including 6 twin pregnancies & $268(86 \%,[81-89])$ & 257 (86\%, [82-90]) & $219(86 \%,[81-90])$ & $136(89 \%,[83-94])$ \\
\hline Twin pregnancy & $6(2 \%,[0.7-4])^{b}$ & $6(2 \%,[0.7-4])^{b}$ & $5(2 \%,[0.6-5])$ & $2(1 \%,[0.2-5])^{b}$ \\
\hline Spontaneous abortion & $32(10 \%,[7-14])$ & $29(10 \%,[7-14])$ & $23(9 \%,[6-13])$ & $12(8 \%,[4-13])$ \\
\hline Therapeutic abortion & $8(3 \%,[1-5])$ & $10(3 \%,[2-6])$ & $8(3 \%,[1-6])$ & $2(1 \%,[0.2-5])$ \\
\hline Still births & $2(1 \%,[0.1-2])^{c}$ & $2(0.7 \%,[0.1-2])^{c}$ & $2(0.8 \%,[0-3])^{c}$ & $0(0 \%,[0-2])$ \\
\hline Ongoing pregnancy & $8(3 \%,[1-5])$ & $5(2 \%,[0.5-4])$ & $8(3 \%,[1-6])$ & $3(2 \%,[0.4-6])$ \\
\hline Live births, including twins & 268 & 257 & 219 & 136 \\
\hline Gestational age in weeks, median (IQR) & $41(39-41)$ & $41(39-41)$ & $41(39-41)$ & $41(39-41)$ \\
\hline Pre-term delivery (<37 weeks) & $24(9 \%,[6-13])$ & $22(9 \%,[5-13])$ & $16(7 \%,[4-12])$ & $16(12 \%,[7-18])$ \\
\hline Birthweight (Kg), median (IQR) & $3.3(3-3.7)$ & $3.4(3-3.7)$ & $3.4(3-3.7)$ & $3.3(2.9-3.7)$ \\
\hline Low birthweight (<2.5 Kg) & $18(7 \%,[4-10])$ & $10(4 \%,[2-7])$ & $12(5 \%,[3-9])$ & $9(7 \%,[3-12])$ \\
\hline Sex (male) & $142(53 \%,[47-59])$ & $143(56 \%,[49-62])$ & 119 (54\%, [47-61]) & $76(56 \%,[47-64])$ \\
\hline Intellectual disability & $1(0.4 \%,[0-2])$ & $2(0.8 \%,[0-3])$ & $1(0.5 \%,[0-3])$ & $1(0.7 \%,[0-4])$ \\
\hline Congenital malformation & $9(3 \%,[1-6])$ & $9(4 \%,[2-7])$ & $10(5 \%,[2-8])$ & $4(3 \%,[1-7])$ \\
\hline
\end{tabular}

Values are presented as numbers and percentages $[95 \% \mathrm{Cl}]$ unless otherwise specified

As before the pregnancies the male patients were exposed to co-medication, one outcome can be declared in several columns

MMF Mycophelonate mofetil, CTC corticosteroid, IQR interquartile range

${ }^{a}$ Transplant to conception time, in years

${ }^{b}$ One of the twin pregnancy was still ongoing at the time of the study

c In both stillbirths, from a twin pregnancy, a pulmonary malformation was discovered

et al. [22] identified 205 pregnancies fathered by male KT recipients exposed to MMF/MPA at the time of conception, and among 194 livebirths, the rate of malformations and prematurity were 3.1 and $11 \%$, respectively. No specific pattern of malformation was identified [22]. Recently, Midtvedt et al. [24] retrospectively compared outcomes in pregnancies fathered by male KT recipients either exposed to MMF/MPA or not at the time of conception. There were 112 patients who fathered 155 children under MMF/ MPA, and 133 patients who fathered 195 children without MMF/MPA exposure. They found no difference in malformations nor pre-term deliveries in children fathered by MMF/MPA exposed compared to $\mathrm{KT}$ recipients not exposed [24]. The outcomes of pregnancies fathered by male transplant recipients appear similar to those of the general population and MPA embryopathies have not been noted in pregnancies fathered by those patients $[21,53]$. Our results add to the available data in the literature, that pregnancies fathered by patients under MMF/MPA at the time of conception do not seem to have more complications than pregnancies in the general population.

\section{Anxiety issues}

To our knowledge, patient anxiety about the impact of immunosuppressive drugs on pregnancies and children has never been previously studied. Our survey reveals a signal of increased anxiety in this population, which is important to take into account to improve patient's quality of life. Among participants who never had children, one-third did not have a desire to father children, without any differences across the centres. It remained a common feeling among men who wanted children after transplantation, as the childless patients reported feeling anxious about exposure to immunosuppressive drugs (Table 6). The design of the survey did not inquire about the reasons of this anxiety, nor its care. Our findings will require further qualitative studies, to better describe the sources of anxiety. A multidisciplinary transplant team, to help KT patients medically as well as psychologically, seems necessary in the light of our findings.

\section{Limitation of the survey}

This study has several limitations, most notably the limited response rate which was less than 50\% despite 
Table 4 Description and outcomes of pregnancies fathered after kidney transplantation according to the fathers' immunosuppressive medication at the time of conception

\begin{tabular}{|c|c|c|c|c|}
\hline Covariate & $\begin{array}{l}\text { Azathioprine } \\
n=59\end{array}$ & $\begin{array}{l}\text { Sirolimus } \\
n=7^{b}\end{array}$ & $\begin{array}{l}\text { Belatacept } \\
n=6^{b}\end{array}$ & $\begin{array}{l}\text { Everolimus } \\
n=5^{b}\end{array}$ \\
\hline Number of recipients & 46 & 7 & 4 & 5 \\
\hline Age, median (IQR), years & $51(44-56)$ & $40(38-48)$ & $39(35-42)$ & $55(37-62)$ \\
\hline Age at conception, median (IQR), years & $34(29-36)$ & $34(29-36)$ & $38(35-39)$ & $37(34-40)$ \\
\hline Transplant to conception time ${ }^{\mathrm{a}}$, median (IQR) & $5(2-9.5)$ & $4(1.5-12)$ & $6(5-8)$ & $7(4-10.8)$ \\
\hline \multicolumn{5}{|l|}{ Pregnancy outcomes } \\
\hline Live births, including 6 twin pregnancies & $55(93 \%,[84-98])$ & 5 & 4 & 5 \\
\hline Twin pregnancy & $1(2 \%,[0-9])$ & 0 & 0 & 1 \\
\hline Spontaneous abortion & $2(3 \%,[0.5-11])$ & 2 & 2 & 0 \\
\hline Therapeutic abortion & $2(3 \%,[0.5-11])$ & 0 & 0 & 1 \\
\hline Still births & $0(0 \%,[0-6])$ & 0 & 0 & 0 \\
\hline Ongoing pregnancy & $1(2 \%,[0-9])$ & 0 & 0 & 0 \\
\hline Live births, including twins & 55 & 5 & 4 & 5 \\
\hline Gestational age in weeks, median (IQR) & $41(39-41)$ & $39(38-40)$ & $38(38-39)$ & $39(36-41)$ \\
\hline Pre-term delivery (<37 weeks) & $5(9 \%,[3-20])$ & 0 & 0 & 2 \\
\hline Birthweight (Kg), median (IQR) & $3.5(3.1-3.6)$ & $3(2.4-3.3)$ & $3.1(2.9-3.2)$ & $3.2(2.9-3.6)$ \\
\hline Low birthweight $(<2.5 \mathrm{Kg})$ & $1(2 \%,[0.1-10])$ & 1 & 0 & 0 \\
\hline Sex (male) & $33(60 \%,[46-73])$ & 3 & 2 & 3 \\
\hline Intellectual disability & $2(4 \%,[0.5-13])$ & 0 & 0 & 0 \\
\hline Congenital malformation & $4(7 \%,[2-17])$ & 0 & 0 & 0 \\
\hline
\end{tabular}

Values are presented as numbers and percentages $[95 \% \mathrm{CI}]$ unless otherwise specified

As before the pregnancies the male patients were exposed to co-medication, one outcome can be declared in several columns

$M M F$ Mycophelonate mofetil, IQR interquartile range

a Transplant to conception time, in years

${ }^{b}$ Due to the small number of events, percentages are not presented

several relaunches to improve participation. Our population may not be representative of the experiences of all male KT recipients. Participation was voluntary and was thus subject to reporting and selection biases. Although the response rate may limit the generalizability of our results, this survey represents to our knowledge one of the largest sampling of pregnancies fathered by male KT recipients. It should also be noted that surveys may accentuate the concerns of a minority of responders, further limiting generalizability.

The use of a questionnaire to collect past events could introduce memory bias. Participants needed to recall events that could have happened over 10-15 years back in time, which could question the validity of the collected data.

Additionally, in addition to immunosuppressive agents, KT recipients are treated with multiple other medications, and thus exposures to various other agents cannot be excluded. As previously discussed, our spontaneous abortion rate is probably under-estimated due to a misunderstanding of the questionnaire by some patients. Information about immunosuppressive drugs of patients who did not father children after KT was not collected, which limits the interpretation of our infertility rate. Moreover, our study lacks information on the graft function, which also influences male KT recipients' ability to conceive. Finally, because of the design of the study, medical information about the mother as well as her potential treatments were not available, even though the mothers' exposure can have a major impact when studying pregnancy outcomes.

\section{Conclusion}

In conclusion, our survey adds further information on the proportion of malformations in the offspring of transplanted men exposed to immunosuppressive drugs, which remains a crucial issue that has lacked evidence to date. Despite the limited response rate, this survey does not provide any warning signal that pregnancies fathered by male patients exposed to immunosuppressive agents, notably the debated MMF/MPA, have more complications than pregnancies in the general population; which is consistent with previous studies.

Even more data will be needed in the future; and health care providers are encouraged to report the outcomes of such pregnancies in the literature. 
Table 5 List of therapeutic abortions and congenital malformations identified among 25 offspring of male kidney transplant recipients exposed to immunosuppressive medication

\begin{tabular}{|c|c|c|c|c|}
\hline \multicolumn{5}{|c|}{ Therapeutic abortion, $n=12$} \\
\hline Year of pregnancy & Year of transplant & Paternal age $\mathrm{a}^{\mathrm{a}}$ & Medical reason for abortion & $\begin{array}{l}\text { Male } K T \text { recipients' medication regimen at } \\
\text { the time of conception }\end{array}$ \\
\hline 1986 & 1981 & NA & Genetic disorder & AZA, prednisone \\
\hline NA & 1994 & NA & Trisomy 21 & MMF/MPA, tacrolimus, prednisone \\
\hline 2005 & 1979 & 31 & Spina bifida and Arnold Chiari & AZA, prednisone \\
\hline 2012 & 2006 & 48 & Ectopic pregnancy & MMF/MPA, cyclosporine \\
\hline 2013 & 2007 & 34 & Trisomy 21 & MMF/MPA, cyclosporine \\
\hline 2014 & 2010 & 36 & missing & MMF/MPA, tacrolimus, prednisone \\
\hline 2015 & 2006 & 34 & missing & MMF/MPA, tacrolimus, prednisone \\
\hline 2016 & 2009 & 40 & missing & MMF/MPA, tacrolimus, prednisone \\
\hline 2016 & 2008 & 35 & missing & Tacrolimus, prednisone \\
\hline 2016 & 2011 & 35 & Multiple malformations & Tacrolimus, everolimus, prednisone \\
\hline 2018 & 2014 & 33 & missing & MMF/MPA, tacrolimus, prednisone \\
\hline 2018 & 2013 & 43 & missing & MMF/MPA, tacrolimus, prednisone \\
\hline \multicolumn{5}{|c|}{ Congenital malformation, $n=13$} \\
\hline Year of birth & Year of transplant & Paternal age $\mathrm{a}^{\mathrm{a}}$ & Congenital malformation & $\begin{array}{l}\text { Male } K T \text { recipients' medication regimen } \\
\text { at the time of conception }\end{array}$ \\
\hline 1998 & 1996 & 33 & Cleft lip and palate & AZA, cyclosporine \\
\hline 2000 & NA & NA & Deafness & AZA, cyclosporine, prednisone \\
\hline 2001 & 1998 & 32 & Congenital phimosis & MMF/MPA, cyclosporine, tacrolimus, prednisone \\
\hline 2001 & 2000 & NA & Cleft lip and palate & AZA, tacrolimus, prednisone \\
\hline 2002 & 1989 & 41 & Complex cardio-facial syndrome & AZA, tacrolimus, prednisone \\
\hline 2005 & 2004 & 34 & Left thumb's agenesis & MMF/MPA, tacrolimus, prednisone \\
\hline 2006 & 1992 & 25 & Pyloric stenosis & MMF/MPA, tacrolimus, prednisone \\
\hline 2009 & 2007 & 21 & Renal hypoplasia & MMF/MPA, tacrolimus \\
\hline 2012 & 2007 & 30 & Hypospadias & MMF/MPA, cyclosporine \\
\hline 2015 & 2011 & 26 & Hypoplastic toes & MMF/MPA, tacrolimus, prednisone \\
\hline 2015 & 2013 & 32 & Urinary tract malformation & MMF/MPA, tacrolimus \\
\hline 2016 & 2010 & 32 & Plagiocephaly & MMF/MPA, tacrolimus, prednisone \\
\hline 2017 & 2006 & 38 & Wolff Parkinson White syndrome & MMF/MPA, tacrolimus, prednisone \\
\hline
\end{tabular}

MMF/MPA Mycophelonate mofetil/Mycophenolic acid, AZA Azathioprine

${ }^{a}$ Age at conception of the pregnancy, in years

Table 6 Participants' feelings regarding a future pregnancy according to their fatherhood status

\begin{tabular}{llll}
\hline Covariate & All patients $(\boldsymbol{n}=1332)$ & $\begin{array}{l}\text { Patients without children } \\
\text { after KT }(\boldsymbol{n}=\mathbf{1 1 0 0})\end{array}$ & $\begin{array}{l}\text { Patients having fathered } \\
\text { after KT }(\boldsymbol{n}=\mathbf{2 3 2})\end{array}$ \\
\hline Future desire to father a child, $\mathrm{n}(\%,[95 \% \mathrm{CI})$ & $175(13 \%,[11-15])$ & $119(11 \%,[9-13])$ & $56(24 \%,[19-30])$ \\
Anxiety regarding a future pregnancy, $\mathrm{n}(\%,[95 \% \mathrm{Cl}])$ & $140(11 \%,[9-12])$ & $106(10 \%,[8-12])$ & $34(15 \%,[10-20])$ \\
Treatment modification to prepare for pregnancy, $\mathrm{n}(\%,[95 \% \mathrm{CI})$ & $50(4 \%,[3-5])$ & $34(3 \%,[2-4])$ & $16(7 \%,[4-11])$ \\
\hline
\end{tabular}




\section{Supplementary Information}

Supplementary information accompanies this paper at https://doi.org/10. 1186/s12882-020-02115-X.

Additional file 1: Supplementary data. Figure S1. Questionnaire. Table S1. Number of included patients and participants according to the centre. Table S2. Male kidney transplant recipients' characteristics according to their paternity status.

\section{Abbreviations}

95\% Cl: 95\% confidence interval; ANSM: Agence Nationale de la Santé et des Médicaments; AZA: Azathioprine; CTC: Corticosteroid; EMA: European Medicines Agency; IQR: Interquartile range; Kg: Kilogram; KT: Kidney transplant; MMF/MPA: Mycophenolate mofetil/mycophenolic acid; NA: Nonapplicable; NTPR: National Transplantation Pregnancy Registry; PKD: Polycystic kidney disease

\section{Acknowledgments}

The authors thank the participating centres of the Spiesser transplant group and the Cristal Registry: Pierre-François Weestel (CHU Amiens, France), JeanFrançois Augusto (CHU Angers, France), Yann Le Meur (CHU Brest, France), Cyril Garrouste (CHU Clermont-Ferrand, France), Jean-Philippe Rérolle (CHU Limoges, France), Eric Thervet (Hôpital Européen Georges-Pompidou, France), Dany Anglicheau (Hôpital Necker AP-HP, France), Antoine Thierry (CHU Poitiers, France), Charlotte Colosio (CHU Reims, France), Joseph Rivalan (CHU Rennes, France), Isabelle Etienne (CHU Rouen, France), Sophie Caillard (CHU Strasbourg, France), and Mathias Büchler (CHU Tours, France).

Questionnaire adapted from the National Transplantation Pregnancy Registry.

\section{Authors' contributions}

AB, MD: study conception, methodology, data collection and analysis, and writing of the manuscript. TL, MD: writing of the manuscript. MO, MSc: data collection and analysis. ATL, MD: manuscript revision. NB, MD-PhD: manuscript revision. VC, MD-PhD: study conception, methodology and writing of the manuscript. BHL, MD-PhD: study conception, methodology and writing of the manuscript. All authors have read and approved the manuscript.

\section{Funding}

This study was funded by a grant from "L'Agence de la Biomédecine". The "Agence de la Biomédecine" reviewed and accepted the study design. The funding financed the postal costs and personnel costs for data collection and data management.

\section{Availability of data and materials}

All data generated or analysed during this study are available from the corresponding author on reasonable request.

\section{Ethics approval and consent to participate}

The study was approved by the ethics committee of $\mathrm{CHU}$ de Caen (France) and was conducted according to the declaration of Helsinki. Informed and written consent to participate in the study was obtained from participants.

\section{Consent for publication}

Not applicable.

\section{Competing interests}

The authors declare that they have no competing interests.

\section{Author details}

${ }^{1}$ Centre Universitaire des Maladies Rénales, CHU de Caen, Avenue de la côte de Nacre, 14033 Caen, Cedex 9, France. ${ }^{2}$ U1086 INSERME - ANTICIPE, Centre Régional de Lutte contre le Cancer, François Baclesse, 14076 Caen, Cedex 5, France. ${ }^{3}$ Unicaen, UFR de Médecine, Normandie Université, 2 rue des Rochambelles, 14032 Caen, Cedex, France.
Received: 31 July 2020 Accepted: 20 October 2020

Published online: 16 November 2020

\section{References}

1. Murray JE, Reid DE, Harrison JH, Merrill JP. Successful pregnancies after human renal transplantation. N Engl J Med. 1963;269:341-3.

2. Deshpande NA, James NT, Kucirka LM, Boyarsky BJ, Garonzik-Wang JM, Montgomery RA, et al. Pregnancy outcomes in kidney transplant recipients: a systematic review and meta-analysis. Am J Transplant. 2011;11:2388-404.

3. Sibanda N, Briggs JD, Davison JM, Johnson RJ, Rudge CJ. Pregnancy after organ transplantation: a report from the UK transplant pregnancy registry. Transplantation. 2007;83:1301-7.

4. Armenti VT, Constantinescu S, Moritz MJ, Davison JM. Pregnancy after transplantation. Transplant Rev. 2008;22:223-40.

5. Coscia LA, Constantinescu S, Moritz MJ, Frank AM, Ramirez CB, Maley WR, et al. Report from the national transplantation pregnancy registry (NTPR): outcomes of pregnancy after transplantation. Clin Transpl. 2010;7:65-85.

6. Coscia LA Constantinescu S, Davison JM, Moritz MJ, Armenti VT. Immunosuppressive drugs and fetal outcome. Best Pract Res Clin Obstet Gynaecol. 2014;28:1174-87.

7. McKay DB, Josephson MA. Pregnancy in recipients of solid organs--effects on mother and child. N Engl J Med. 2006:354:1281-93.

8. Davison JM, Bailey DJ. Pregnancy following renal transplantation. J Obstet Gynaecol Res. 2003;29:227-33.

9. Kallen B, Westgren M, Aberg A, Olausson PO. Pregnancy outcome after maternal organ transplantation in Sweden. BJOG. 2005:112:904-9.

10. Armenti VT, Ahlswede BA, Moritz MJ, Jarrell BE. National transplantation pregnancy registry: analysis of pregnancy outcomes of female kidney recipients with relation to time interval from transplant to conception. Transplant Proc. 1993;25:1036-7.

11. Shah S, Venkatesan RL, Gupta A, Sanghavi MK, Welge J, Johansen R, et al. Pregnancy outcomes in women with kidney transplant: metaanalysis and systematic review. BMC Nephrol. 2019;20:24.

12. Sifontis NM, Coscia LA, Constantinescu S, Lavelanet AF, Moritz MJ, Armenti VT. Pregnancy outcomes in solid organ transplant recipients with exposure to mycophenolate mofetil or sirolimus. Transplantation. 2006;82:1698-702.

13. Anderka MT, Lin AE, Abuelo DN, Mitchell AA, Rasmussen SA. Reviewing the evidence for mycophenolate mofetil as a new teratogen: case report and review of the literature. Am J Med Genet A. 2009:149A:1241-8.

14. Dei Malatesta MF, Rocca B, Gentile T, Hadjistilianou T, Borri M, de Francesco $\mathrm{S}$, et al. A case of coloboma in a newborn to a woman taking mycophenolate mofetil in pregnancy after kidney transplantation. Transplant Proc. 2009:41:1407-9.

15. Hoeltzenbein M, Elefant E, Vial T, Finkel-Pekarsky V, Stephens S, Clementi M, et al. Teratogenicity of mycophenolate confirmed in a prospective study of the European network of teratology information services. Am J Med Genet A. 2012;158A:588-96.

16. Le Ray C, Coulomb A, Elefant E, Frydman R, Audibert F. Mycophenolate mofetil in pregnancy after renal transplantation: a case of major fetal malformations. Obstet Gynecol. 2004;103:1091-4.

17. Perez-Aytes A, Ledo A, Boso V, Sáenz P, Roma E, Poveda JL, et al. In utero exposure to mycophenolate mofetil: a characteristic phenotype? Am J Med Genet A. 2008;146A:1-7.

18. FDA. CellCept. Drug label information. https://www.accessdata.fda.gov/ drugsatfda_docs/label/2007/050722s015,050723s012,050758s013,050759s01 8lbl.pdf. Published 2007. Accessed 7 May 2020.

19. McKay DB, Josephson MA, Armenti VT, August P, Coscia LA, Davis CL, et al. Reproduction and transplantation: report on the AST consensus conference on reproductive issues and transplantation. Am J Transplant. 2005;5:1592-9.

20. EBPG Expert Group on Renal Transplantation. European best practice guidelines for renal transplantation. Section IV: Long-term management of the transplant recipient. IV.10. Pregnancy in renal transplant recipients. Nephrol Dial Transplant. 2002;17 Suppl 4:50-5.

21. Le HL, Francke M, Andrews LM, De Winter BCM, Van Gelder T, Hesselink DA Usage of Tacrolimus and Mycophenolic acid during conception, pregnancy and lactation, and its implications for therapeutic drug monitoring: a systematic critical review. Ther Drug Monit. 2020:42(4):518-31.

22. Jones A, Clary MJ, McDermott E, Coscia LA, Constantinescu S, Moritz MJ, et al. Outcomes of pregnancies fathered by solid-organ transplant recipients exposed to mycophenolic acid products. Prog Transplant. 2013;23:153-7. 
23. Morken NH, Diaz-Garcia C, Reisaeter AV, Foss A, Leivestad T, Geiran O, et al. Obstetric and neonatal outcome of pregnancies fathered by males on immunosuppression after solid organ transplantation. Am J Transplant. 2015;15:1666-73.

24. Midtvedt K, Bergan S, Reisaeter AV, Vikse BE, Asberg A. Exposure to mycophenolate and fatherhood. Transplantation. 2017;101:e214-7.

25. Boobes Y, Bernieh B, Saadi H, Raafat Al Hakim M, Abouchacra S. Gonadal dysfunction and infertility in kidney transplant patients receiving sirolimus. Int Urol Nephrol. 2010;42:493-8.

26. Huyghe E, Zairi A, Nohra J, Kamar N, Plante P, Rostaing L. Gonadal impact of target of rapamycin inhibitors (sirolimus and everolimus) in male patients: an overview. Transpl Int. 2007;20:305-11.

27. Tondolo V, Citterio F, Panocchia N, Nanni G, Favi E, Brescia A, et al. Gonadal function and immunosuppressive therapy after renal transplantation. Transplant Proc. 2005;37:1915-7.

28. Skrzypek J, Krause W. Azoospermia in a renal transplant recipient during sirolimus (rapamycin) treatment. Andrologia. 2007;39:198-9.

29. Zuber J, Anglicheau D, Elie C, Bererhi L, Timsit M-O, Mamzer-Bruneel M-F, et al. Sirolimus may reduce fertility in male renal transplant recipients. Am J Transplant. 2008;8:1471-9.

30. Scialli AR, Bailey G, Beyer BK, Bøgh IB, Breslin WJ, Chen CL, et al. Potential seminal transport of pharmaceuticals to the conceptus. Reprod Toxicol. 2015;58:213-21.

31. Roche. Mycophenolate mofetil (CellCept): serious risk of teratogenicity important new pregnancy prevention advice for women and men. https://

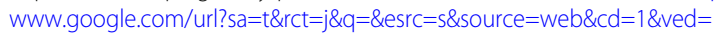
2ahUKEwiovqix_froAhWyZDUKHfZiDGkQFjAAegQIARAB\&url=https\%3A\%2 F\%2Fwww.hpra.ie\%2Fdocs\%2Fdefault-source\%2Fdefault-documentlibrary\%2Fimportant-safety-information\%2D\%2D-cellcept-(mycophenolatemofetil).pdf\%3Fsfvrsn\%3D0\&usg=AOvVaw3LM_4Orwhg4O51nfbRVwLA. Published 2015. Accessed 7 May 2020.

32. European Medicines Agency. EMA recommends additional measures to prevent use of mycophenolate in pregnancy. http://www.ema.europa.eu/ ema/index.jsp?curl=pages/. Published 2015. Accessed 7 May 2020

33. ANSM. Mycophénolate (Cellcept ${ }^{\oplus}$ et génériques et Myfortic ${ }^{\circledast}$ ) : nouvelles contre-indications et mesures de prévention de la grossesse en raison du risque important de tératogénicité - Point d'Information. https://www.ansm. sante.fr/S-informer/Points-d-information-Points-d-information/ Mycophenolate-Cellcept-R-et-generiques-et-Myfortic-R-nouvelles-contreindications-et-mesures-de-prevention-de-la-grossesse-en-raison-du-risqueimportant-de-teratogenicite-Point-d-Information. Published 2015. Accessed 7 May 2020.

34. Anonymous. Mycophenolate: updated recommendations for contraception men and women. https://www.ema.europa.eu/en/news/mycophenolateupdated-recommendations-contraception-men-women. Published 2018. Accessed 7 May 2020.

35. Damkier P, Passier A, Bo Petersen L, Havnen G, Thestrup Pedersen AJ. Changing of the guards: EMA warning on paternal use of mycophenolate mofetil: an unnecessary and insufficiently substantiated precaution. Birth Defects Res A Clin Mol Teratol. 2016;106:860-1.

36. Midtvedt K, Asberg A. Mycophenolate acid and balancing the risk for male allograft recipients. Transplantation. 2017;101:e39.

37. Kuypers DR, Van Mieghem T, Meijers B, Claes K. Updated manufacturer and European medicines agency recommendations on the use of mycophenolate acid: balancing the risks for male allograft recipients. Transplantation. 2016;100:e50-1.

38. Transplant Pregnancy Registry International. A division of gift of life institute. https://www.transplantpregnancyregistry.org/participation/. Accessed 7 May 2020.

39. Holdsworth S, Atkins RC, de Kretser DM. The pituitary-testicular axis in men with chronic renal failure. N Engl J Med. 1977;296:1245-9.

40. Handelsman DJ, McDowell IF, Caterson ID, Tiller DJ, Hall BM, Turtle JR. Testicular function after renal transplantation: comparison of Cyclosporin a with azathioprine and prednisone combination regimes. Clin Nephrol. 1984; 22:144-8.

41. INSERM. Infertilité, des difficultés à concevoir d'origines multiples. https:// www.inserm.fr/information-en-sante/dossiers-information/infertilite. Accessed 7 May 2020

42. Agarwal A, Mulgund A, Hamada A, Chyatte MR. A unique view on male infertility around the globe. Reprod Biol Endocrinol. 2015;13:37.
43. Okutman O, Rhouma MB, Benkhalifa M, Muller J, Viville S. Genetic evaluation of patients with non-syndromic male infertility. J Assist Reprod Genet. 2018; 35:1939-51.

44. Krausz C. Male infertility: pathogenesis and clinical diagnosis. Best Pract Res Clin Endocrinol Metab. 2011;25:271-85.

45. Delabaere A, Huchon C, Deffieux X, Beucher G, Gallot V, Nedellec S, et al. Epidemiology of loss pregnancy. J Gynecol Obstet Biol Reprod. 2014;43: 764-75.

46. Agence de la Biomédecine. Rapport d'activité annuel des centres pluridisciplinaires de diagnostic prénatal 2015. https://www.agencebiomedecine.fr/annexes/bilan2016/donnees/diag-prenat/02-centres/pdf/ cpdpn.pdf. Accessed 7 May 2020

47. Blondel B, Cuttini M, Hindori-Mohangoo AD, Gissler M, Loghi M, Prunet C, et al. How do late terminations of pregnancy affect comparisons of stillbirth rates in Europe? Analyses of aggregated routine data from the euro-Peristat project. Bjog. 2018;125:226-34.

48. INSERM et DRESS. Enquête nationale périnatale Rapport 2016. Les naissances et les établissements Situation et évolution depuis 2010. http:// www.xn\%2D\%2Depop-inserm-ebb.fr/wp-content/uploads/2017/10/ENP2 016_rapport_complet.pdf. Published 2017. Accessed 7 May 2020.

49. Morris JK, Springett AL, Greenlees R, Loane M, Addor M-C, Arriola L, et al. Trends in congenital anomalies in Europe from 1980 to 2012. PLoS One. 2018;13:e0194986.

50. Galea R, Said E. Infantile hypertrophic pyloric stenosis: an epidemiological review. Neonatal Netw. 2018;37:197-204.

51. Bréaud J, Guys JM. Phimosis: medical treatment or circumcision? Arch Pediatrie. 2005;12:1424-32.

52. Chhabra L, Goyal A, Benham M. Wolff Parkinson white syndrome (WPW). Treasure Island, FL: StatPearls Publishing; 2020.

53. Coscia LA, Armenti DP, King RW, Sifontis NM, Constantinescu S, Moritz MJ. Update on the teratogenicity of maternal mycophenolate mofetil. J Pediatr Genet. 2015;4:42-55.

\section{Publisher's Note}

Springer Nature remains neutral with regard to jurisdictional claims in published maps and institutional affiliations.

Ready to submit your research? Choose BMC and benefit from:

- fast, convenient online submission

- thorough peer review by experienced researchers in your field

- rapid publication on acceptance

- support for research data, including large and complex data types

- gold Open Access which fosters wider collaboration and increased citations

- maximum visibility for your research: over $100 \mathrm{M}$ website views per year

At BMC, research is always in progress.

Learn more biomedcentral.com/submissions 